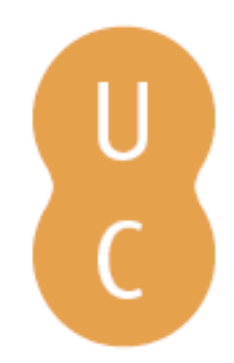

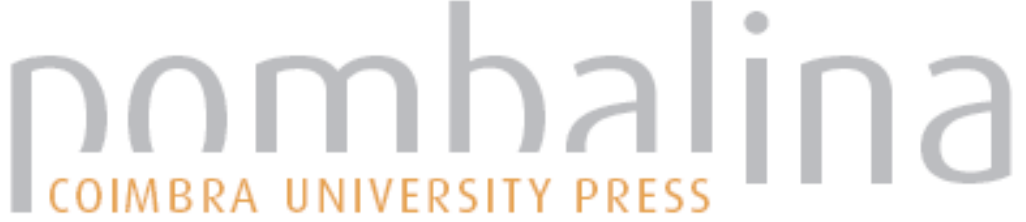

\section{Consideração em torno do usus scribendi de Luís de Camões}

\author{
Autor(es): Bechara, Evanildo
}

Publicado por: Imprensa da Universidade de Coimbra

URL

persistente: $\quad$ URI:http://hdl.handle.net/10316.2/30772

DOI: $\quad$ DOI:http://dx.doi.org/10.14195/978-989-26-0569-2_12

Accessed : $\quad$ 26-Apr-2023 14:50:29

A navegação consulta e descarregamento dos títulos inseridos nas Bibliotecas Digitais UC Digitalis, UC Pombalina e UC Impactum, pressupõem a aceitação plena e sem reservas dos Termos e Condições de Uso destas Bibliotecas Digitais, disponíveis em https://digitalis.uc.pt/pt-pt/termos.

Conforme exposto nos referidos Termos e Condições de Uso, o descarregamento de títulos de acesso restrito requer uma licença válida de autorização devendo o utilizador aceder ao(s) documento(s) a partir de um endereço de IP da instituição detentora da supramencionada licença.

Ao utilizador é apenas permitido o descarregamento para uso pessoal, pelo que o emprego do(s) título(s) descarregado(s) para outro fim, designadamente comercial, carece de autorização do respetivo autor ou editor da obra.

Na medida em que todas as obras da UC Digitalis se encontram protegidas pelo Código do Direito de Autor e Direitos Conexos e demais legislação aplicável, toda a cópia, parcial ou total, deste documento, nos casos em que é legalmente admitida, deverá conter ou fazer-se acompanhar por este aviso. 


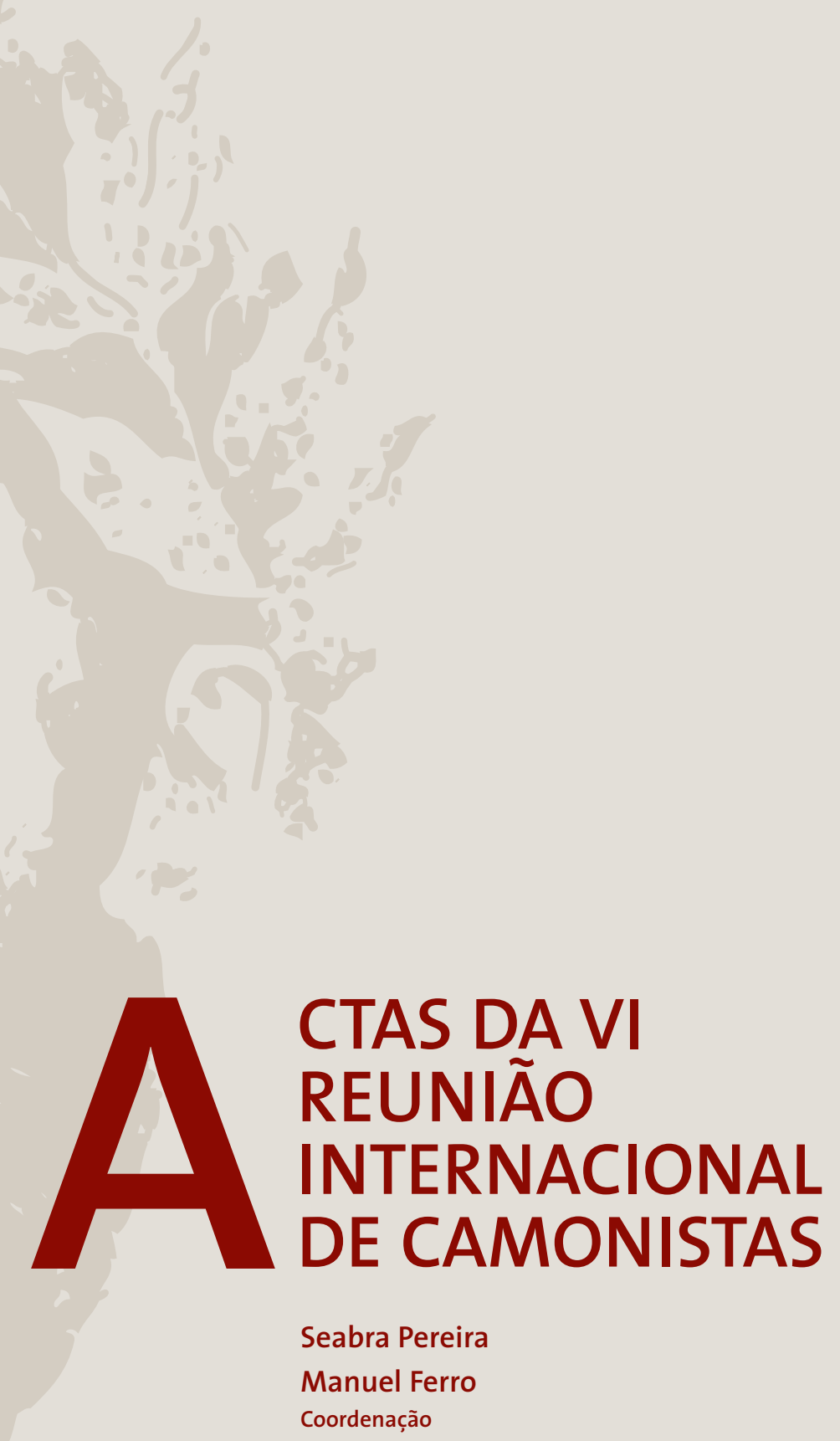


Evanildo Bechara

UERJ-UFF. Rio de Janeiro

\section{CONSIDERAÇÓES EM TORNO DO USUS SCRIBENDI DE LUÍS DE CAMÓES}

À medida que se vão dando passos decisivos no apuro da fixação textual da obra épica e lírica de Luís de Camóes, mais e mais se vão juntando os tênues e fragmentários elementos para o levantamento ainda e sempre provisório do usus scribendi do grande vate lusitano, cujo valor intrínseco e cuja repercussão literária, lingüística, estética e cultural, enfim, são os alicerces que incentivam e sustentam, mais uma vez, esta VI Reunião Internacional de Camonistas, ao abrigo da Universidade de Coimbra, desta Coimbra táo cara ao nosso poeta.

De importância primária entre os critérios internos a serem levados em conta na escolha de uma lição preferencialmente a outras liçóes distintas que apresenta a tradição manuscrita ou impressa, há-de o crítico não perder de vista que nada, neste terreno da crítica textual, tem carater "universal". Como judiciosamente comenta G. Pasquali,

"Facile e difficile non sono termini assoluti, e quel che è difficile, cioè inconsueto, per noi, può essere stato facile per nomini di altre età. Il giudizio sopra facilità o difficultà di una lezione sarà tanto più sicuro, quanto meglio il giudice conoscerà le consuetudini di linguaggio e di pensiero delle età che l'hanno trasmessa, che possono averla coniata (...) Un critico siffato è un ideale che nessumo può incarnare in sé perfettamente, ma al quale ognuno ha il dovere di cercare di avvicinarsi" ${ }^{1}$

Graças a reiteradas leituras críticas dos textos e ao acúmulo de estudos no campo do pensamento e da arte, da gramática, da fonologia e da ortografia, do léxico e da

\footnotetext{
${ }^{1}$ G. Pasquali, Storia della tradizione e critica del testo. 2a ed. Firenze, 1952 (rist. anastatica, Milano, 1974).
} 
métrica, vamos hoje conhecendo melhor a língua e o verso de Camóes; mas estamos ainda longe do levantamento que nos permita falar, com a segurança que se deseja ideal, sobre usus scribendi ou dicendi do poeta, e dele nos servirmos na solução de problemas que a crítica textual nos impóe.

Se este desideratum é complexo quando o crítico trabalha com autor que se caracteriza por um monoestilismo - como é o caso, até certo ponto, de escritores que se pautaram pelo modelo da chamada escola vicentina ou por aqueles épicos que giraram em torno da influência e do prestígio da tradição de Os Lusíadas -, mostrar-se-á a questão muito mais complexa quando se trata de autores, como o nosso patrono, que nos legou textos pertencentes a vários gêneros literários. Optar, em casos assim, como às vezes se vem fazendo, por uma variante textual que tem a seu favor o peso quantitativo da maior frequência, pode ser um procedimento válido pelo que tem de objetividade, para não chamá-lo "mecanicista", mas que poderá deixar na sombra uma particularidade de inovação estilística original, fruto que é do saber expressivo do autor ${ }^{2}$.

Estudos de língua e de crítica textual esquecidos da particular atenção que se deve dar a tais recursos inovadores, porque a norma náo ofereceu ao artista aquilo de que precisava naquele momento de criação, têm chegado a liçôes e opções menos certeiras. Dois exemplos curiosos dão deste fato testemunho precioso.

A não flexão do adjetivo português, no conhecido verso de $O$ Hissope "A nossa português casta linguagem» (canto V, verso 134), tem servido de fundamento à afirmação de filólogos e literatos de que este fato de gramática teria chegado até o século XVIII, testemunhado pelo uso de Cruz e Silva. Segundo até onde pude averiguar, a lição parece ter começado nesta nota, aliás mal interpretada ao depois, do erudito português José Maria da Costa e Silva a passagem de Sá de Miranda em texto recolhido e comentado no vol. II do Ensaio biográfico sobre os melhores poetas portugueses:

"Os adjetivos em or, em ês e alguns outros eram antigamente comum de dous; por isso achamos tantas vezes nos autores antigos e mesmo em João de Barros: cidade competidor, uma português, uma holandês, etc. Mesmo muitos tempos depois deste uso ter cessado, Antônio Dinis da Cruz e Silva, que decerto sabia a sua língua, não duvidou dizer no Hissope: "É [a] nossa português casta linguagem”, V, 133 (Lisboa, 1851, p. 48).

Do Ensaio o comentário transformou-se em lição nas excelentes gramáticas que para o português escreveram Carl von Reinhardstoettner ${ }^{3}$ e J. Cornu ${ }^{4}$, e daí estava aberto o caminho para que a afirmação passasse às gramáticas, históricas ou não; assim

\footnotetext{
${ }^{2}$ Cf. as sensatas ponderaçóes de Armando Balduino em Manuale di filologia italiana (Firenze, Sansoni, 1979) e, para os autores greco-latinos, de Bertold Maurenbrecher em Grundlagen der klassïschen Philologie (Stuttgart, W. Violet, 1908).

${ }^{3}$ Grammatik der portugiesischen Sprache (Strassburg, 1879, p. 185).

${ }^{4}$ Grammatik der portugiesischen Sprache (Strassburg, 1888, p. 97).
} 
está nos compêndios escritos por João Ribeiro, J. J. Nunes, A. Nascurtes, Ismael de Lima Coutinho, entre outros.

No caso da não flexão de português há aspectos interessantes a considerar, um para a cronologia da flexão nominal e outro para uma particularidade diafásica. Quanto ao primeiro, já o nosso primeiro gramático Fernão de Oliveira registrara a existência de portuguesa ao seu tempo como fato incipiente, depois de referir-se a invariabilidade de português como fato de norma. Em relação ao segundo aspecto, é curioso assinalar que João de Barros, em suas Décadas - talvez pelo caráter arcaizante de estilo e de língua do gênero histórico -, opta pela forma invariável do termo, mas na sua obra gramatical - em que o arcaísmo seria recurso destoante - só emprega o termo marcado portuguesa, bem como francesa, embora continue a usar, por exemplo, espanhol invariável.

Retornando ao recurso estilístico usado por Cruz e Silva, deveu-se, no meu parecer, a uma caracterização, com certa dose de ironia, do pensar e do sentir do padre Mestre que, dialogando com Lara, condena a invasáo de expressóes francesas a manchar a pureza do idioma pátrio, do padre Mestre que o autor orna com rica tradição haurida nos venerandos clássicos do português e do latim ${ }^{5}$. Não se trata, pois, de um fato vivo ainda na língua do seu tempo; é sim um belo exemplo do que Eugenio Coseriu ${ }^{6}$ chama diacronia "subjetiva" ou "diacronia dos falantes", isto é, intuída como tal pelos próprios falantes e que muitas vezes náo coincide com a diacronia objetiva que o historiador da língua estabelece.

Tanto é assim que, fora desse momento de discurso de apologia à antiga tradição, o padre Mestre só se socorre da forma portuguesa, com marca de feminino.

Tal recurso estilístico não perturbaria apenas a descrição linguística; refletir-se-ia também na crítica textual. Uma cópia d'O Hissope existente na Biblioteca de Coimbra, de 1795, a cargo de Domingos dos Santos Morais, estranhando naturalmente o fato, adota:

\footnotetext{
5 "Desta audácia, senhor, deste descoco,

Que entre nós, sem limite, vai grassando,

Quem mais sente as terríveis conseqüências

É a nossa português casta linguagem

Que em tantas traduçôes corre envasada

(Traduçôes que merecem ser queimadas!)

Em mil termos e frases galícanas!

Ah! se as marmóreas campas levantando,

Saíssem dos sepulcros, onde jazem

Suas honradas cinzas, os antigos

Lusitanos varôes, que com a pena,

Ou com a espada e lança pátria honraram,

Os novos idiotismos escutando,

A mesclada dicção, bastardos termos,

Com que enfeitar intentam seus escritos

Estes novos, ridículos autores

(Como se a bela e fértil língua nossa,

Primogênita filha da latina

Precisasse de estranhos atavios)" (pp. 177-178 da ed. de 1879).

${ }^{6}$ Eugenio Coseriu, Lecciones de lingüistica general, Madrid, Gredos, 1981, pp. 296-297.
} 
"E’o nosso português, casta linguagem.

A edição de Lisboa de 1834 opta por:

E' a nossa portuguesa linguagem.'

O consciente editor José Ramos Coelho adota a versão mais difundida, aceitando registar como intencional a não flexão do adjetivo e, muito agudamente, justifica sua opção desta maneira:

"Conservamos - a nossa português-

feminino antiquado, por julgarmos que

o poeta o pôs intencionalmente na boca

do padre jubilado, o qual era, como se

vê, inimigo do modernismo em ma-

téria de língua” (p. 309 da ed. de 1879).

Outro grande sabedor da língua da qual extraía a seiva do seu estilo engenhoso foi, sabemo-lo todos, o Pe. Antônio Vieira. Entre os momentos de suspensão da norma para fins expressivos está o intrigante início de frase "Me avisam que (...)».

Numa carta dirigida a Capistrano de Abreu, datada de 9 de setembro de 1926, o notável sintaticista brasileiro M. Said Ali refere-se à estranha prática de linguagem e tece a seguinte engenhosa explicação ${ }^{7}$ :

"O afamado Me avisam que não atribuo à influência do falar brasileiro. Está em carta datada de Roma. Por aquela época Vieira recorria às vezes a um modo de dizer estrangeiro, para cumprir o provérbio: "A bom entendedor meia palavra basta”. Queria o padre significar que a notícia procedia de boca italiana”

(Correspondência, III, pp. 204-205)

Infelizmente o comentário ficou por aí, não tratando do problema nem em carta nem em artigo específico. Todavia, uma análise do contexto em que ocorre o fato sintático e de outras situaçóes em que o missivista, em missão do governo português, pede discrição de seus avisos e informaçóes, bem pode justificar a explicação dada por Said Ali. Eis o texto comentado até aqui:

"Me avisam em muito secreto [o sub-

linhado é meu] que Espanha tem resoluto

romper a guerra com França primeiro

que ela o faça $(. .) "$.

O missivista insiste na descrição em outras cartas:

\footnotetext{
${ }^{7}$ Correspondência de Capistrano de Abreu. Ed. de José Honório Rodrigues. Rio de Janeiro, MEC-JNL, 1954.

${ }^{8}$ Cartas do Padre Antonio Vieira. Ed. J. Lúcio d’Azevedo. Lisboa, Imprensa Nacional.
} 
"Tive aqui notícias por via certa

(mas de nenhum modo passe de V. Sa) que

o decreto se tinha mandado a Roma (...)

(Ibid., II, 414)

“(...) de que me pareceu avisar a

V. Sa . para que S. A. se confirme na cau-

tela com que o não tem querido ouvir;

mas, se esta notícia chegar a tempo,

sirva-se V. Sa. de que se náo saiba o

autor.

(Ibid., II, 434)

Passando a problemas de crítica textual que podem encontrar solução no usus scribendi ou dicendi de Camóes, começo por trazer à baila os discutidos versos de $O s$ Lusiadas em que se procura ver falha do copista ou do editor por aparecerem versos rimados "à custa da mesma palavra»?

"Das águas se lhe antolha que saíam,

Par'ele os largos passos inclinando,

Dous homens que mui velhos pareciam,

De aspeito, inda que agreste, venerando.

Das pontas dos cabelos lhe saíam

Gotas, que o corpo todo vão banhando;

A cor da pele baça e denegrida,

A barba hirsuta, intonsa, mas comprida"

(IV, 71)

O competentíssimo Epifânio Dias relutou em aceitar a hipótese de erro tipográfico nos lugares em que editores do passado interferiram na lição dos textos com data de 1572, sob a alegação de que, argumentavam, dificilmente o épico macularia o poema com versos rimados com repetição do mesmo significante, ainda que alguns tivessem significado diferente, quando a mácula teria seu peso atenuado. Num desses passos que registram a interferência abusiva de editores, Epifânio teve oportunidade de advertir:

"A rima da mesma palavra (ou de homófonos) - aqui de "profundo" empregado como substantivo com "profundo " empregado como adjetivo - ocorre em outros lugares do poema: "jeito" em I, 81, "pressa” em V, 32, “viram” (de "vir" e de "virar") em II, 68, não falando da rima de palavras simples com um seu composto, como "fundo" e "profundo" em IX, 40. No suposto $1^{\circ}$ manuscrito de FS lia-se "facundo" neste lugar (comentário a IV, 102) ${ }^{10}$.

${ }^{9}$ Antônio Salgado Júnior, Luís de Camóes - Obra completa, Rio de Janeiro, Aguilar, 1963, p. 884.

${ }^{10}$ A. Epifânio da Silva Dias, Os Lusíadas, 2a ed., Porto, 1916, vol. I, p. 266. Acerca desta obra pronunciou-se Leite de Vasconcelos com o peso do seu saber: "A crítica poderá descobrir nesta, como em todas as obras 
Com ter procedido com tanta cautela e acerto neste comentário, contudo inclinouse a aceitar a proposta de retificação do segundo saíram do $5^{\circ}$ verso da citada estança, alternando-o para caíam, sem apresentar nenhum argumento, limitando-se a informar: "a corr [eçâo], nem por todos aceita, é já antiga».

Entre os que não o acompanharam na emenda está outro competente camonista, José Maria Rodrigues, que reuniu nos Estudos sobre Os Lusiadas, resenhando criticamente a 2a edição do poema a cargo de Epifânio Dias, juntamente com os comentários deste grande mestre, o mais rico repositório de informaçóes com que até hoje contamos para o usus scribendi e dicendi de Camôes e, até certo ponto, para o nosso conhecimento da língua do século XVI.

Apesar do peso de sua autoridade, a contraposição de José Maria Rodrigues cingiu-se à questão meramente interpretativa, não indo, segundo suponho, ao âmago do problema:

"O contexto mostra que se deve manter o verbo primitivo. As gotas não "caíam" diretamente no chão; "saíam" dos cabelos e escorriam pelo corpo abaixo."11

Acredito que as razóes para a manutenção do saíram que se quer destronar, por gralha tipográfica, se devem a motivos de ordem mais elevada e aí encontrar solução. Em primeiro lugar, náo se pode perder de vista que os "dous homens, que mui velhos pareciam» representam a antropomorfização dos rios Ganges e Indo, que nascem de antigos e altos montes, como duas claras e altas fontes.

Ora, se nos lembrarmos de que, na expressão do competente mestre Orlando Ribeiro, Camôes foi o mais geógrafo dos nossos poetas, será mais fácil compreendermos a habilidade com que usava a fraseologia náutica e marítima. Sair o rio, a fonte é expressão padronizada da fraseologia desse domínio semântico, onde sair concorre com nascer para indicar o lugar onde nasce ou surge uma fonte ou um rio. Dentre muitos outros exemplos que o poeta deve ter lido nas fontes históricas - e até ouvido na sua vivência no mar -, cite-se a seguinte passagem de João de Barros, onde nascer alterna com sair, com predominância deste último:

"O primeiro destes rios nasce de duas fontes ao Oriente de Chaul quase per distância de quinze léguas em altura entre dezoito e dezenove graus: ao rio que sai de uma das fontes, que jaz mais ao Norte, chamam Crusná; e ao que sai da que está ao Sul, Benhorá, e depois que se adjuntam em um corpo, chamam-lhe Ganga, o qual vai sair na foz do ilustre rio Gange entre estes dous lugares (...)" (Da Ásia, Década $1^{\mathrm{a}}$ parte $2^{\mathrm{a}}, \mathrm{p}$. 292 da ed. de 1777).

humanas, alguns senóes; mas quando virá outra edição que derrube o glorioso monumento levantado a Camóes pelo Sr. Epifânio?» (Epiphanio Dias - Sua vida e labor scientifico, Lisboa, Imprensa Nacional, 1922, p. 31).

${ }^{11}$ José Maria Rodrigues, Estudos sobre Os Lusíadas (1ª ed. pela Revista de Lingua Portuguesa, de Laudelino Freire, e, em 2a ed., pela Editora Lucerna, Rio de Janeiro, 1991). 
O próprio poema nos fornece mais de uma vez o emprego do verbo sair nessa aplicação especial; note-se o paralelismo descritivo da estança que acabei de analisar com esta do Canto VII, 18:

"Lá bem no grande monte, que cortando

Tão larga terra, toda Asia discorre

As fontes saem, donde vem marcando

Os rios, cuja grã corrente morre

No mar Índico (...)"

Dir-se-á que servir-se de tal sistema de explicação do usus scribendi pode chegar às raias do arbítrio; mas, como lembra G. Pasquali, é melhor uma conjectura engenhosa em que se crê ou em que se têm boas razóes de crença, do que um sistema excessivamente mecânico. ${ }^{12}$

Aqui e ali a tradição manuscrita da lírica camoniana com que vem trabalhando o filólogo brasileiro Leodegário A. de Azevedo Filho, apresenta " 0 " em contextos em que a

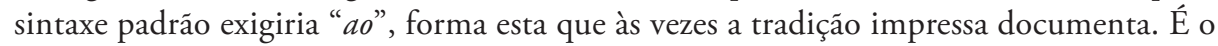
caso de se perguntar se, em tais momentos, houve interferência corretiva de RH ou de RI, ou a fonte por que os editores se orientaram já apresentava a forma canônica " $a o^{\text {". }}$

Exemplo disto é a passagem que o filólogo brasileiro comenta no recente volume dedicado às Cançóes ${ }^{13}$. Na que começa por "Com força desusada», p. 129, o testemunho dos manuscritos LF e Ms. Jur. oferece:

"que asi como o doente,"

enquanto RH, RI e FS apresentam a lição ao doente.

Aqui está um uso que pode incluir-se como de possível responsabilidade do poeta, pois que se trata de fenômeno linguístico existente no seu tempo e que se prolonga até nossos dias, embora em estilo informal. À época de Camóes o fenômeno podia ocorrer em estilo formal, e até em Os Lusíadas parece ter-se o poeta servido dele em duas passagens que a crítica textual resolveu alterar, subtraindo talvez o autor uma característica linguística que lhe era cara: a convivência equilibrada das formas antigas com as do moderno erudito ao gosto renascentista, convivência já posta em relevo, entre outros, por F. Adolfo Coelho e José Maria Rodrigues.

A primeira passagem, conservada nos dois textos com data de 1572 e em ediçóes posteriores, está em IV, 41, 8:

"A sublime bandeira castelhana

Foi derribada os pés da lusitana."

\footnotetext{
12 G. Pasquali, op. cit., p. 125

${ }^{13}$ Leodegário A. de Azevedo Filho, Lírica de Camóes, 3, tomo I - Cançôes. Lisboa, Imprensa Nacional - Casa da Moeda, 1995, p. 129.
} 
Epifânio Dias aceita a emenda aos pés e adianta que a correção "é já antiga». A segunda está em IX, 74, 3:

"Vendo rosto o férreo carro erguido

Depois de agasalhar a emenda:

Vendo no rosto o férreo cano erguido,"

anota o ilustre sintaticista:

"Man[uel] Corrêa escreveu "vendo no rosto"; a ed. de 1597 traz "ó rosto" (o que equivale, na pronúncia popular a "ao rosto", lição que Trigoso, ao que me parece, não muito fundadamente, acha preferível.”

Outra vez temos todos de lamentar não ter Epifânio explicitado as razóes por que considerava com um pouco fundamento a preferência de Trigoso, já que a preposição estaria a meu ver perfeitamente adequada: erguer o cano à altura do rosto.

Nas mesmas condiçóes está o $3^{\circ}$ verso do soneto "Alegres campos, verdes arvoredos", segundo a lição ministrada por TT (manuscrito 2209 do Arquivo Nacional da Torre do Tombo $)^{14}$.

"que en vós debuscais ô natural,"

contra o testemunho unânime de CrB e LF ao natural. O editor brasileiro, rejeitando - por coerência da norma que adotou - a lição de TT, atribui o $\hat{o}$ a influência galega, pondo de lado a possibilidade de ser este um fato também do português.

Um caso que está à espera de maior investigação no esforço para o levantamento do usus scribendi e dicendi de Camóes é o que toca a formas do tipo em que entram -bil e -vel, como em afábil, impossíbil, etc.

Epifânio Dias, no Registo Filológico de sua edição do poema, informa-nos:

"Os adjetivos derivados terminados em “-vel” têm nos Lusíadas a forma latina "-bil” (-bilis) (...)"

Leodegário ${ }^{15}$, rigorosamente de acordo com seu princípio de tomar, nas decisôes relativas ao usus scribendi do poeta, o testemunho de Os Lusíadas, ao encontrar em manuscritos erigidos por básicos ou merececedores de crédito, lições discordantes, prefere rejeitá-las em favor da lição do poema épico. Assim é que, embora os versos 11 e 14, em rima, do soneto "Apolo e as nove Musas d[e]scantando", ofereçam na tradição manuscrita de base os finais em -vel — invisivel (aliás, feliz solução do editor,

\footnotetext{
${ }^{14}$ Id., 2, Sonetos, t. 1, 1987, p. 76.

15 Id., ibid., t. 2, p. 329.
} 
em vez de impossivel) e possivel —, intervém no texto, alterando-o para invisíbil e possíbil respectivamente, sob o peso da liçáo unânime de impossíbil de Os Lusíadas.

Se o poeta preferiu, na épica, as formas alatinadas em -bil, isso não significa que, noutro gênero, não pudesse optar pelas formas com feição vernácula; é até possível que, aqui e ali, assim procedesse para marcar diafasicamente a natureza ou a feição formal de cada gênero, como, aliás, procedeu enquanto autor de peças teatrais e de cartas.

Campo ainda mais escorregadio para o levantamento do usus scribendi e dicendi em obras desses tempos afastados é o que diz respeito a opções ortográficas, onde interferem não só fatores de ordem lingüística - como o privilegiamento da pronúncia à instável e débil norma ortográfica vigente, ou a alteraçóes devidas a fenômenos de dissimilações e metafonias -, mas também fatores de ordem cultural e estética, como o peso da influência erudita nas grafias latinizantes.

De igual maneira, a observação se estende ao hábito de escrever juntos ou separados os elementos integrantes de palavras de formação secundária. Não se pode aceitar sem certo ar de suspeita a afirmação de que o usus scribendi do poeta impóe, por exemplo, grafias do tipo em fim, em quanto, em duas palavras, por ser esta a lição unânime de $O s$ Lusíadas, o que denuncia, para os que adotam tal afirmação, que, na época do poeta, ainda não estava definitivamente consolidada a justaposição dos termos. Partindo dessa premissa, interfere-se na lição apresentada pela tradição manuscrita de base, quando náo acerta o passo com o exemplo ministrado pelo poema. Faltam-nos estudos para adotar com tranqüilidade o preceito, ainda mais porque na própria epopéia aparece duplicidade de grafias do tipo de atento/a tento, também / táo bem, não faltando o par enfim lem fim (VIII, 77 e 78).

Lembra bem M. Barbi que são delicadas questóes que não se podem resolver nem com o ouvido moderno nem os nossos hábitos ortográficos, mas com paciente e minucioso estudo do uso comum e do uso literário desses tempos passados ${ }^{16}$.

No estado atual do nosso conhecimento da língua do século XVI, são de muita prudência as seguintes ponderaçóes de Antônio Salgado Junior na Introdução geral à Obra completa, de Luís de Camóes ${ }^{17}$ :

"Ao tempo de Camões não há lugar, ao que parece, para olhar as grafias como reveladoras da pronúncia particular a um grupo ou a um indivíduo, como sucede com as grafias dos séculos posteriores. Bem sabemos que a oscilação na grafia de certas palavras pode levar à conclusão contrária, isto é, que essa duplicidade indica dupla pronuncia e o direito em que cada um se sentia de a registar (...). Não podemos acreditar, efetivamente, que Camóes tivesse tantas duplas pronúncias de vogais quantas são as palavras em que se manifesta dupla

\footnotetext{
${ }^{16}$ M. Barbi, La nuova filologia, Firenze, Sansoni, 1977, p. 4.

${ }^{17}$ Id., ibid., t. 1, p. 145.
} 
grafia. Pensamos que a oscilação é, neste caso e nos casos similares, meramente gráfica, reveladora não da pronúncia oscilante do autor, mas das oscilaçôes da simples pronúncia dos vários compositores tipográficos intervenientes. Se foi o autor quem reviu, cruzou os braços, atendendo a que, afinal, tanto fazia uma ou outra das grafias, porque uma e outra existiam"18

\footnotetext{
${ }^{18}$ A. Salgado Junior, op. cit..
} 